choices are influenced by other (partial) systems, so that authority of the (first) system is constrained. For instance, if a therapy for cancer costing 10 million dollars per person were discovered then medicine would fali prey to politics, and the choice of which patients should be cured would not be left to doctors.

According to Luhmann when such a situation takes place, there is a need for a further reflective thinking in the partial system. However, in the case of medicine the situation is difficult because medicine has not developed any reflective style resulting in a 'theory of medicine' as for example economics, or law, which have developed sophisticated 'theories of economics' and 'theories of law'.

Luhmann suggests that the development of a theory of medicine could provide a way of looking at new problems arising in medicine, and that such a way could be a viable alternative to the introduction of ethical committees, which is sometimes suggested.

Finally, he tries to point towards such a new theory of medicine, saying that the concept of health is too wide and fuzzy to be helpful, and that a more suitable framework would be provided by the problem of pain, as this reveals the special relationships between the individual's conscience and his body.

I am not so sure that Luhmann's suggestion of a more developed theory of medicine would suffice to solve the new problems arising in medicine. As an economist is not necessarily a good businessman, so it is not certain that a theoretician of medicine can come up with better practical solutions. Bearing this in mind I do not agree with Luhmann's strong opposition to ethical committees, which in my judgement can be useful.

Luhmann's view is interesting however because it suggests a way of facing the new ethical problems arising in medicine. He thinks that a widening of the perspective is sufficient for medicine to find the solution. In this sense the end of a narrow technicalism is enough for the beginning of a more humane medicine.

This general view seems to be adopted by some proponents of the Catholic position; whilst in nonreligious factions, the new problems are given a different solution from traditional ones, for example, the S. Raffaele Hospital's proposal is to put such new problems in a new setting of 'widened' medicine so that hard choices are softened. I am not sure that such an approach will produce good results, as I do not agree with Cardinal C M Martini when, in his contribution to the book, he says that contemporary democratic non-religious societies are unable to present ethical values in their educational systems. I think that a secular society can and will produce a more humane medicine, more fitted to solve the new moral problems that we have to face.

RAFFAELE PRODOMO Doctor of Forensic Medicine Via G Santacroce 15, Napoli, Italy

\section{Case Studies in Nursing Ethics}

Robert M Veatch and Sarah T Fry, 312 pages, New York, \$17.50, hbk, J P Lippincott Co, 1987.

The text is based on the premise that nursing ethics is a discrete sub-category of bioethics, using the same principles and discipline of analysis but applied to issues of particular relevance to nurses and their work.

In this book, underlying ethics and values in nursing are initially explored with a sound account of ethical conflicts in caring for patients, followed by a discussion of the nurse and moral authority. However, the main thrust of this book and, to my mind its special contribution, is contained in Part II where ethical principles are described and illustrated at length by case examples. Part III then becomes rather more familiar as problem areas, such as abortion, technical innovations, experimentation and informed consent are covered.

There is little doubt that the combination of expertise from an ethicist and a nurse has resulted in a particularly stimulating book. They have succeeded in relating the discipline of ethical analysis to several areas of health care which are relatively poorly recognised or understood. Guidelines for adjudicating ethical disputes are provided with care and with full reference to the role of codes in decision-making. Although they employ a conventional framework for applying ethical principles (such headings as fidelity, avoiding harm, justice, autonomy, veracity being used) for a wide range of dilemmas the presentation of case material makes this original, stimulating and educational.

In all, one hundred and fifteen actual cases are used, with legal references provided as appropriate. Some pertain to quite basic issues of how to allocate time for care between patients, while others concern disagreements between the values and actions of other professionals. In all cases the analysis from a moral, legal and clinical viewpoint is penetrating and clear. As one might expect, the reader is left to adjudicate and decide the verdict, which certainly extends the period one requires to devote to this work.

While Veatch and Fry have contributed well to the literature on nursing ethics, it would be sad if others in health care were excluded from readership. Despite the specific nature of some American case material, this work should really benefit the broader field of health-care ethics on both sides of the Atlantic.

JENIFER WILSON-BARNETT Department of Nursing Studies, King's College London (KQC)

\section{Medicine in Contemporary Society: King's College Studies 1986-7}

Peter Byrne, Editor, 156 pages, London, £16.95, hbk,

King's Fund Publishing Office, 1987.

This book has been compiled from public lectures given at King's College, London in the spring of 1986, and covers issues contemporary to that time, many of which continue to be prominent in ethical discussions. Thus, as always, anything to do with sex abortion, in vitro fertilisation, the pill for under-age girls, sexual abuse of children and women's place in medicine - is well to the fore. As usual arguments on these issues seem to have been formed after, and not before, judgements.

It is a pleasure, therefore to come across some of the other issues contained within this volume. The question of the use of animals in medical research is considered by Peter Byrne and by putting it alongside the use of children for research, I think that he illuminates the subject with a welcome dose of common sense. The logical consequence of the anti-vivisectionist argument is the use of sub-standard humans - the lame, the halt and the blind - instead.

Arnold Simanowitz is also topical on the question of 'no-fault' compensation for medical accidents. He unearths the fact that prior to the current massive increase in defence organisation 